\title{
AMENDMENTS
}

\section{Author Correction: The hidden benefits of high-speed rail}

\author{
Armin Schmutzler (D) \\ Correction to: Nature Climate Change https://doi.org/10.1038/s41558-021-01199-z, published online 25 October 2021.
}

The version of this article initially published was based on descriptions of emissions reductions discussed in the original article ${ }^{1}$, which has since been amended to correct for a calculation error ${ }^{2}$. In the third paragraph now reading "Relying on extensive traffic-monitoring data and standard statistical methods (difference-in-difference), the Article by Lin et al. shows that the massive expansion of the Chinese high-speed rail network since 2006 has led to a reduction in annual GHG emissions equivalent to just above 11 million tons of $\mathrm{CO}_{2}$, which corresponds to around $1.3 \%$ of the total GHG emissions in China's transport sector," the text "above 11 million tons" originally read "below 15 million tons" while the text "around 1.3\%" originally read "1.75\%." Further, in the fourth paragraph, the third sentence now reading "For instance, the authors calculate that the beneficial effect of the high-speed rail system would have been around twice as high in a hypothetical scenario with the Chinese electricity mix replaced by the French structure," the text "around twice as high" has replaced "almost twice as high." The changes have been made in the HTML and PDF versions of the article.

\section{References}

1. Lin, Y., Qin, Y., Jing, W. \& Xu, M. Nat. Clim. Chang. https://doi.org/10.1038/s41558-021-01190-8 (2021).

2. Lin, Y., Qin, Y., Jing, W. \& Xu, M. Nat. Clim. Chang. https://doi.org/10.1038/s41558-021-01253-w (2021).

Published online: 20 January 2022

https://doi.org/10.1038/s41558-022-01288-7

๑) Springer Nature Limited 2022

\section{Publisher Correction: Risk transfers support adaptation}

\section{Roman Hoffmann (D)}

Correction to: Nature Climate Change https://doi.org/10.1038/s41558-021-01231-2, published online 22 November 2021.

In the version of this article initially published, there were errors in affiliations 1 and 2, listing "University of Vienna" in place of "IIASA, OeAW, University of Vienna." The affiliations have been shortened to a single affiliation now reading "International Institute for Applied Systems Analysis (IIASA) \& Vienna Institute of Demography (OeAW), Wittgenstein Centre for Demography and Global Human Capital (IIASA, OeAW, University of Vienna), Laxenburg, Austria."

The changes have been made to the online version of the article.

Published online: 4 January 2022

https://doi.org/10.1038/s41558-021-01267-4

๑) Springer Nature Limited 2022 